\title{
QUINOLINIUM DICHROMATE OXIDATION OF HETEROCYCLIC CARBOXYLIC ACIDS
}

\author{
Hauzachin Suante and Mahendra K. Mahanti* \\ Department of Chemistry, North - Eastern Hill University \\ Shillong 793022, India \\ e-mail : mkmahanti@yahoo.com ; Fax : 91-364-2550486
}

\begin{abstract}
Heterocyclic carboxylic acids were oxidized to the corresponding hydroxy-substituted acids by quinolinium dichromate in sulfuric acid, in $50 \%(\mathrm{v} / \mathrm{v})$ acetic acid-water as solvent. The kinetic results supported a mechanistic pathway proceeding via a rate-determining decomposition of the chromate ester.
\end{abstract}

\section{Introduction}

Quinolinium dichromate [QDC, $\left(\mathrm{C}_{9} \mathrm{H}_{7} \mathrm{NH}^{+}\right)_{2} \mathrm{Cr}_{2} \mathrm{O}_{7}{ }^{2-}$ ] has been used for diverse transformations such as the oxidation of hydrocarbons, ${ }^{\prime}$ oxidative cleavage of unsaturated compounds, ${ }^{2}$ oxidation of cyclic and bicyclic alcohols, ${ }^{3}$ amino acids, ${ }^{4}$ diols, ${ }^{5} \alpha$-hydroxy acids, ${ }^{6}$ ketones, ${ }^{7}$ and aldehydes. ${ }^{8.9}$ There have been earlier reports of the decarboxylation of pyridinecarboxylic acids ${ }^{10.12}$ and pyrimidinecarboxylic acids. ${ }^{13}$ With a view to establish the site of reaction in heterocyclic carboxylic acids, we have carried out a kinetic study on the oxidation of heterocyclic carboxylic acids (pyridine-2-carboxylic acid, pyridine-3-carboxylic acid and pyridine-4-carboxylic acid) by QDC, in acid medium, in 50\% acetic acid-water $(\mathrm{v} / \mathrm{v})$, under nitrogen.

\section{Results and Discussion}

The method used for the kinetic measurements has been described earlier. ${ }^{5}$ The rate of oxidation of heterocyclic carboxylic acids was found to be dependent on the first powers of the concentrations of each - substrate, oxidant and acid (Table 1). In the range of acid concentrations used, the dichromate ion (or its protonated form) has been shown to be the predominant species." The observed order of reactivity was : pyridine-2carboxylic acid > pyridine-4-carboxylic acid > pyridine-3-carboxylic acid. The presence of the carboxylic group in the 2-position would influence the distribution of charge as a result of the steric configuration. This steric arrangement would not be possible either with 3-carboxylic or with 4-carboxylic acids. Steric considerations would thus favour the mechanistic pathway for the reaction as proceeding via the formation of a cyclic intermediate involving an attack by the oxygen (of the oxidant) at the position adjacent to the carboxylic group.

The sequence of reactions has been shown in the Scheme. The attack of the protonated QDC (PQ) on the substrate (S) was favoured by the formation of a cyclic chromate ester (E). In order to test the feature of a cleavage of the carbon-hydrogen bond in the rate-determining step of the reaction, an evaluation of the kinetic isotope effect for the hydrogen atom in pyridine-2-carboxylic acid- $\mathrm{d}_{3}$ was carried out. It was observed that pyridine2-carboxylic acid reacted faster than pyridine-2-carboxylic acid $\mathrm{d}_{3}$ by a factor of 2.4 . which indicated that the rate determining step of the reaction involved a cleavage of the carbonhydrogen bond in pyridine-2-carboxylic acid. The mechanism envisaged the formation of a cyclic intermediate in which the carbon (of the substrate) would be bonded to the oxygen 
$\left(\mathrm{C}_{9} \mathrm{H}_{7} \mathrm{~N}^{+} \mathrm{H}\right)_{2} \mathrm{Cr}_{2} \mathrm{O}_{7}^{2-}+2 \mathrm{H}^{+} \stackrel{\mathrm{K}}{\rightleftharpoons}$

(QDC)<smiles>O=C(O)C1CCCCN1</smiles>

(5)

Pyridine-2-carboxylic acid<smiles></smiles>

(PQ)

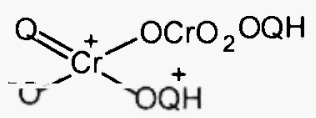

(PQ)<smiles>[O][Ge]1(O)CC[C@H]2CCC[C@H](O2)C(=O)O1</smiles>

(E)

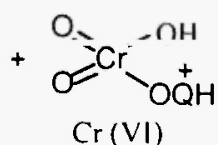

monomer<smiles>O=C(O[Cl+2]([O-])[OH2+])c1ncccc1O</smiles>

$\downarrow \mathrm{H}_{2} \mathrm{O}$<smiles>O=C(O)c1ncccc1O</smiles>

3-Hydroxypyridine-2-carboxylic acid<smiles>O=[Co](O)O</smiles>

Cr(IV)

$$
\mathrm{Cr}(\mathrm{IV})+\mathrm{Cr}(\mathrm{VI}) \stackrel{\text { fast })}{\longrightarrow} 2 \mathrm{Cr}(\mathrm{V}) \stackrel{\text { substrate }}{\longrightarrow} 2 \mathrm{Cr}(\mathrm{III})
$$

\section{Scheme}


Table 1: Rate constants for the Oxidation of Heterocyclic Carboxylic Acids by QDC, in $50 \%$ acetic acid-water at $50^{\circ} \mathrm{C}$.

\begin{tabular}{cccccc} 
[Substrate] & $10^{2}$ & {$[\mathrm{QDC}] \times 10^{3}$} & {$\left[\mathrm{H}_{2} \mathrm{SO}_{4}\right]$} & \multicolumn{3}{c}{$10^{4} \mathrm{k} / \mathrm{s}^{-1}$} \\
\cline { 5 - 6 } $\mathrm{mol} \mathrm{dm}^{-3}$ & $\mathrm{~mol} \mathrm{dm}^{-3}$ & $\mathrm{~mol} \mathrm{dm}^{-3}$ & 1 & 2 & 3 \\
\hline 1.0 & 1.0 & 3.0 & 1.72 & 1.48 & 1.64 \\
5.0 & 1.0 & 3.0 & 8.68 & 7.47 & 8.20 \\
10 & 1.0 & 3.0 & 17.5 & 15.0 & 16.5 \\
1.0 & 0.75 & 3.0 & 1.76 & 1.49 & 1.60 \\
1.0 & 0.50 & 3.0 & 1.67 & 1.46 & 1.63 \\
1.0 & 0.10 & 3.0 & 1.65 & 1.47 & 1.62 \\
1.0 & 1.0 & 3.5 & 2.01 & 1.71 & 1.93 \\
1.0 & 1.0 & 4.0 & 2.34 & 1.96 & 2.20
\end{tabular}

Note: 1: Pyridine-2-carboxylic acid; 2: Pyridine-3-carboxylic acid; 3: Pyridine-4-carboxylic acid. 
(of the oxidant). Such an electrocyclic mechanism involved six electrons; being a Hückel-type system $(4 n+2)$, this was an allowed process. ${ }^{14}$

\section{Experimental}

The oxidation of heterocyclic carboxylic acids (pyridine-2-carboxylic acid, pyridine-3carboxylic acid and pyridine-4-carboxylic acid) by QDC resulted in the formation of the corresponding hydroxycarboxylic acids. The oxidation reactions were carried out as follows: To $15 \mathrm{ml}$ of water cooled in ice, concentrated $\mathrm{H}_{2} \mathrm{SO}_{4}(7.9 \mathrm{~g}, 0.08 \mathrm{~mol} \mathrm{dm}$ ) was added slowly, with constant cooling. The acid solution was cooled to room temperature, quinolinium dichromate $\left(4.76 \mathrm{~g}, 0.01 \mathrm{~mol} \mathrm{dm}^{-3}\right)$ was added and the mixture warmed to $50^{\circ} \mathrm{C}$ for complete dissolution of the QDC. To this mixture, $0.015 \mathrm{~mol} \mathrm{dm}^{-3}$ of substrate $(0.46 \mathrm{~g})$, taken in $25 \mathrm{ml}$ of $50 \%$ acetic acid-water solution, was added. The reaction mixture was stirred at $50^{\circ} \mathrm{C}$ for $24 \mathrm{~h}$ under nitrogen. The organic layer was extracted thrice with ether (25 $\mathrm{ml}$ each time), and the combined organic extracts were washed with water and dried over anhydrous $\mathrm{Na}_{2} \mathrm{SO}_{4}$. The oxidized products (3-hydroxypyridine-2-carboxylic acid from pyridine-2-carboxylic acid; 2-hydroxypyridine-3-carboxylic acid from pyridine-3-carboxylic acid: 3-hydroxypyridine-4-carboxylic acid from pyridine-4-carboxylic acid) were obtained after complete removal of ether (yields $\approx 85-90 \%$ ).

Acknowledgements. Financial support from the Department of Science and Technology, New Delhi, under the Fund for Infrastructure in Science and Technology (FIST) is gratefully acknowledged.

\section{References}

(1) G. (. Sarma and M. K. Mahanti, Oxidation Commun., 13, 224 (1990); 15, 177 (1992).

(2) I. Nongkynrih and M. K. Mahanti, J. Org. Chem., 58, 4925 (1993); Bull. Chem. Soc. Japan., 67, 2320 (1994).

(3) I. Nongkynrih and M. K. Mahanti, Bull. Chem. Soc. Japan., 68, 2320 (1995); 69, 1403 (1996).

(4) E.Karim and M. K. Mahanti, Oxidation Commun., 15, 211 (1992); 19, 582 (1996); 21, 559 (1998).

(5) B. Kuotsu, E. Tiewsoh, A. Debroy and M. K. Mahanti, J. Org. Chem., 61, 8875 (1996).

(6) R. Kharmutee, A. Debroy and M. K. Mahanti, Oxidation Commun., 21, 553 (1998).

(7) S. Das and M. K. Mahanti, Oxidation Commun., 23, 459 (2000).

(8) G. S. Chaubey and M.K.Mahanti, Oxidation Commun., 23, 500 (2000).

(9) G.S. Chaubey, S. Das and M.K.Mahanti, Heterocyclic Commun., 8, 497 (2002); Bull. Chem. Soc. Jpn., 75, 2215 (2002)

(10) G.E.Junn, G.K.J.Lee and H. Thimm, Can. J. Chem., 50, 3017 (1972)

(11) G.E.Dunn and H.F.Thimm, Can. J. Chem., 55, 1342 (1977)

(12) G.E.Dunn, H.F.Thimm and R.K. Mohanty, Can. J. Chem., 57, 1098 (1979)

(13) G.E.Dunn, E.A.Lawler and A.B.Yamashita, Can. J. Chem., 55, 2478 (1977)

(14) 1. S. Littler, Tetrahedron, 27, 81(1971).

\section{Received on July 14, 2003.}

